\section{METHODOLOGY FOR RISK} \section{ASSESSMENT OF NOISE EFFECTS AT WORKPLACE MICHAELA BALAZIKOVA ${ }^{1}$, MIRIAM ANDREJIOVA ${ }^{1}$, BARBORA WYSOCZANSKA}

\author{
${ }^{1}$ Faculty of Engineering, Technical University of Kosice, Kosice, \\ Slovakia \\ 2 Faculty of Aeronautics, Technical University of Kosice, Kosice, \\ Slovakia
}

DOI: 10.17973/MMSJ.2019_12_2019007

michaela.balazikova@tuke.sk

Noise is pervasive in everyday life and can cause two kinds of health effects - auditory and non-auditory health effects. The most investigated non-auditory health endpoints for noise exposure are perceived disturbance and annoyance, cognitive impairment (mainly in children), sleep disturbance, and cardiovascular health. The article presents case study of nonauditory effects of noise on humans. This study assessed the exposure of noise on respondents, especially on their cardiovascular system. Measurement results are statistically evaluated and consulted with experts. The measurement was repeating after one year and the results were also statistically evaluated and compared to results measured one year before and that is the main strange of this article. The final part of this article is comparison of results from two experimental measurements. The paper proposes a methodology of noise risk assessment, taking into consideration legislative requirements as well as non-auditory effects of noise. The article is a continuation of the article: STUDY OF NON-AUDITING EFFECTS OF NOISE, which was published in the MM Science Journal in Juni 2016.

KEYWORDS noise, risk, non-auditory noise effects, workplace safety

\section{INTRODUCTION}

The adverse effects of noise on health have been intensely explored in the past 50 years [Argalášová 2014]. Noise derived from industrial activities is considered as an important occupational risk [Meddeb 2016]. Noise nuisance in industry, particularly in manufacturing plants, is more crucial than in other working areas [Razavi 2014]. Occupational noise exposure has been linked to numerous adverse health effects [Deshaies 2015]. Moreover, the daily exposure of workers to elevated noise levels can cause hearing loss [Meddeb 2016]. The effects of exposure to noise on the human organism are subject to the specific characteristics of the noise, such as the level of noise, frequency, intensity, and exposure time, impulsiveness, intermittency, duration of noise influence and also individual susceptibility [Vianna 2015], [Nilsson 2007], [Prashanth 2008]. Furthermore, sex, health status, occupation, personality, sensitivity, adaptability, and other factors are also closely related. Human beings are continuously exposed to noise in different daily activities, so it is important to develop tools for evaluating the annoyance occurring during leisure time, at work and at home [Nilsson 2007]. Although the reported discomforts are mainly focused on direct hearing impairment, noise can also have serious physiological and psychological consequences, including heart disease, drowsiness and lack of concentration [Molesworth 2013]. Sound becomes noise when it causes adverse health effects, including annoyance, sleep disturbance, cognitive impairment, mental or physiological disorders, stress reactions, endocrine imbalance including hearing loss and cardiovascular disorders [Babisch 2011]. Exposure to noise hinders communication between workers and may also result in different type of physical, physiological and psychological effects on workers [Basner 2014]. Effects of exposure to noise on workers have been divided into two significant groups auditory or non-auditory. The auditory effects include hearing impairment and permanent hearing loss due to excessive noise exposure. The non-auditory effects include stress, related physiological and behavioral effects [Ismaila 2014]. The auditory system is continuously analysing acoustic information, including unwanted and disturbing sound, which is filtered and interpreted by different cortical (conscious perception and processing) and sub-cortical brain structures (non-conscious perception and processing) [Babisch 2017]. There is ample evidence that occupational noise exposure is also linked with cardiovascular diseases [Prashanth 2008]. The cardiovascular effects of noise have been the source of growing interest and they have been intensely explored in the last 50 years. One of the most explored hypotheses is that persistent noise stress increases the risk of cardiovascular disorders, including high blood pressure (hypertension) and ischemic heart disease [Argalášová-Sobotová 2014]. Continuous exposure to noise is reported to have many adverse effects, both physiological and psychological, and it is a very serious problem among people working in an industrial environment [Šolc 2011]. The three general physiological responses to sound are voluntary musculature mediated by the somatic nervous system, smooth muscles and glands mediated by the visceral nervous system, and the neuroendocrine system [Prashanth 2008].

\section{MATERIALS AND METHODS / MEASUREMENT}

The aim of the paper is to point out the influence of physical factor (noise) on human health, concretely on the cardiovascular system, which subsequently affects the quality of work activity. Case study of non-auditory effects of noise on selected group was guided by eight individual steps: 1 . Formulation experimental tasks, 2 . The measured input variables and plan the experiment, 3. Implementation of the experiment, 4 . Conditions and time of measurement, 5 . Selection and editing of measuring points, 6. Measurement procedures and measurement parameters, 7. Evaluation of experimental data, 8. Interpretation and application of the results of the experiment. Experimental task consisted also in repeated measurement over a period of one year, which was realized with the same group of respondents. Measurement took place in the same conditions, with the same technology and working activity. Microclimate conditions and also other factors at work at point of measurement remained unchanged. Technical equipment was operated with the same worker.

The experimental group consisted of fifteen students from 21 to 30 years of age, $60 \%$ of whom were males. This is measured in diffuse fields. Respondents during the measurement were standing (not performing movement), their eyes were open. Heart rate measurements took place gradually. For excluding a significant effect on heart rate of respondents and for more reliable results were implemented measures like covering eyes and respondents were at rest before the experiment. According to the questionnaire responses, it can be stated that no one in the observed sample of people suffers from significant health problems, their BMI index ranges from 18.5 to 24.9, which is considered normal, and health risks related to overweight or underweight are minimal. Majority of respondents were not 
under medical treatment and only one person smokes. The questionnaire showed no factors that could affect the test results.

Basic numeric data of the respondents, their age, height and weight are listed in Table 1.

Table 1. Parameter characteristics of the respondents involved in the experiment $(n=15)$

\begin{tabular}{lcccc}
\hline Parameters & Mean & $\begin{array}{c}\text { Standard } \\
\text { deviation }\end{array}$ & Maximum & Minimum \\
\hline Age (years) & 23.40 & 3.09 & 30 & 21 \\
Height (cm) & 174.07 & 8.48 & 192 & 160 \\
Weight (kg) & 72 & 16.04 & 96 & 50 \\
\hline
\end{tabular}

Measuring point took place in the woodworking workshop. This experiment was measured in working order. The measurement took place before midday. Table 2 presents microclimate conditions (atmospheric pressure, air temperature, air humidity) during experimental measurement in the workplace.

Table 2. Microclimate conditions during measurement in the workplace

\begin{tabular}{cc}
\hline \multicolumn{2}{c}{ Microclimate conditions } \\
\hline Atmospheric pressure & $994 \mathrm{hPa}$ \\
Air temperature & $19{ }^{\circ} \mathrm{C}$ \\
Air humidity & $54 \%$ \\
\hline
\end{tabular}

The measurement was carried out in the workplace (hall) with dimensions of $4 \times 6 \times 7 \mathrm{~m}$, the hall is bricked. Experimental measurement was in the middle of the hall. Due to elimination of factors affecting respondents, background noise was eliminated, i.e. all machines in the workplace (hall) were at the time of the experiment turned off. The measurement was conducted during woodworking. A milling cutter of $1400 \mathrm{~W}$ input power was used.

This measurement was performed in terms of standard ISO 9612:2009(en) Acoustics - Determination of occupational noise exposure - Engineering method. The microphone was placed 1.5 $\mathrm{m}$ above the ground near the noise source.

It was measured equivalent noise exposure level $L_{A, e q}$, which is the Sound Pressure Level in $\mathrm{dB}$, equivalent to the total Sound Energy over a given period of time. It was measured heart rate of respondents, which is the speed of the heartbeat measured by the number of contractions of the heart per minute (bpm).

\subsection{The measuring instruments}

The measurements were made by the instruments:

- sound analyser 2250. Measured data were recorded using the BZ 5503 software,

- heart activity was monitored using the ECG testing device and recorded by OMRON ECG Viewer software.

\subsection{Measurement procedures}

Measurement procedures and also measurement of parameters of the influence of noise on the heart activity were measured as follows:

- ECG record before the presence of individuals in the noisy environment - first heart rate was measured respondents in a quiet room out of service measurement lasted 30 minutes (BEFORE 1- first experimental measurement, BEFORE 2measurement after a year)

- ECG record during the operation of noisy machinery. Then respondents entered into operation for noise source - for milling plates. While in operation were re-measured heart rate measurement took 1 hour. (DURING 1- first experimental measurement, DURING 2- measurement after a year)

- ECG record after the operation of noisy machinery was completed, Respondents were returned to the out of service for a quiet room, and after 1 hour they were again measured heart rates. (AFTER 1- first experimental measurement, AFTER 2measurement after a year)

Measured noise level $L_{A, \text { eq }}$ in the measurement place was at the time of operation $95.4 \mathrm{~dB}, L_{A, e q}$ in a quiet room out of service was $48,4 \mathrm{~dB}$.

The following values were recorded:

- $L_{A, \min }=62.7 \mathrm{~dB}$,

- $L_{A, \max }=101.3 \mathrm{~dB}$,

- $L_{A, e q}=95.4 \mathrm{~dB}$.

The noise was during the measurement steady.

\section{RESULTS AND DISCUSSION}

Table 3 presents parametric data of 15 respondents during experimental measurement. Average age of respondents is 23.4 years, average height is $174.07 \mathrm{~cm}$ and average weight is $72 \mathrm{~kg}$. Table presents also average, standard deviation, maximum and minimum heart rate of respondents before, during and after exposure in noisy environment.

Table 3. Parametric data of the respondents participating in the experiment $(n=15)$

\begin{tabular}{|c|c|c|c|c|c|}
\hline \multicolumn{2}{|c|}{ Parameters } & Mean & $\begin{array}{l}\text { Standard } \\
\text { deviation }\end{array}$ & Maximum & $\begin{array}{c}\text { Minimu } \\
\mathrm{m}\end{array}$ \\
\hline \multicolumn{2}{|c|}{ Age (years) } & 23.40 & 3.09 & 30 & 21 \\
\hline \multicolumn{2}{|c|}{ Height (cm) } & $\begin{array}{c}174.0 \\
7\end{array}$ & 8.48 & 192 & 160 \\
\hline \multicolumn{2}{|c|}{ Weight (kg) } & 72 & 16.04 & 96 & 50 \\
\hline & $\begin{array}{l}\text { Before } \\
\text { exposure }\end{array}$ & 76.8 & 18.80 & 107 & 57 \\
\hline \multirow[t]{2}{*}{$\begin{array}{l}\text { Heart } \\
\text { rate }\end{array}$} & $\begin{array}{l}\text { During } \\
\text { exposure }\end{array}$ & 82.53 & 14.37 & 107 & 61 \\
\hline & $\begin{array}{l}\text { After } \\
\text { exposure }\end{array}$ & 80.93 & 12.72 & 107 & 64 \\
\hline
\end{tabular}

We used the Friedman test to verify whether the heart rate of the experiment participants changed at random or due to noise present in the environment [Knežo 2011]. It results from the tests that the null hypothesis about random influences on the heart rate can be rejected (the value of test statistics $9.5, p$-value is 0.009). It implies that the heart rate depends on the environment of the experiment participants.

With Shapiro-Wilk test we verify normality of data. The results of the testing show that normality condition is not fulfilled in the first set- before staying in noisy environment (BEFORE1), ( $p$ value $=0.018$ ).

Multiple comparisons of post-hoc tests prove that there is evincible difference between the heart rate of the respondents before and during their presence in the noisy environment. The heart rate values rose, which means the heart activity increased during the operation of noisy machinery. Similarly, their heart rate values before and after exposure to noise differed.

Figure 1 shows the statistically evaluated heart rate of respondents with chart of averages and $95 \%$-confidence interval in first measurement. 


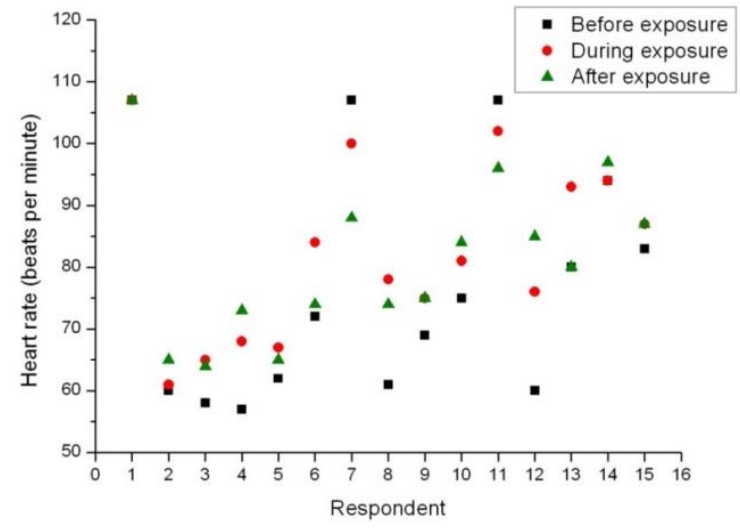

Figure 1. Chart of averages and $95 \%$ - confidence interval from first measurement

\subsection{The results of measurement repeatability non-auditory effects of noise impact after 1 year}

After one year the measurement of non-auditory effect of noise was repeated. The measurement was conducted during the same woodworking, in the same place. Table 4 presents parametric data of 15 respondent's participing in this experiment. Respondents are the same like in first experimental measurement, but their age, height and weight has changed, also their heart rate during measurement.

Table 4. Parametric data of the respondents participating in the experiment after year $(n=15)$

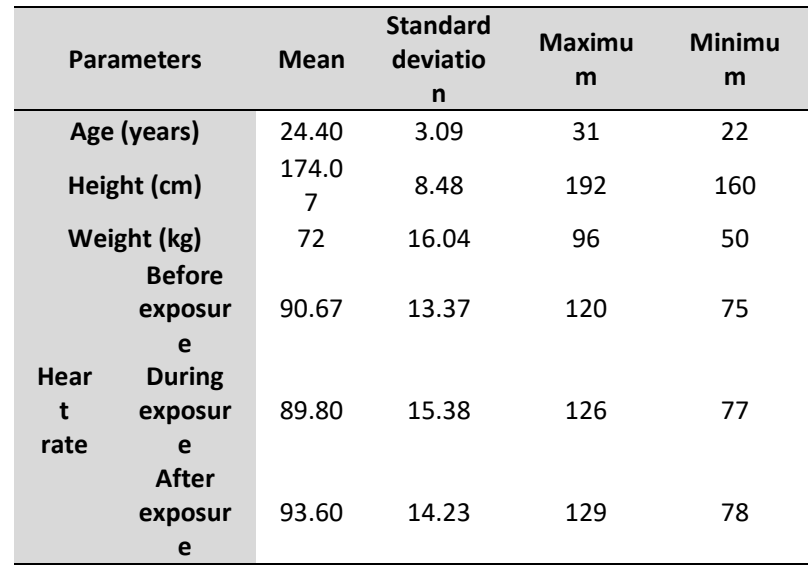

With Shapiro-Wilk test we verify normality of data. The results of the testing show that normality condition is not fulfilled in the second set- during staying in noisy environment (DURING2) ( $p$ value $=0.003<a$ alfa $=0.05$ ).

We used the Friedman test to verify whether the heart rate of the experiment participants changed at random or due to noise present in the environment. Value of test statistics is 5.8. It results from the tests that the null hypothesis about random influences on the heart rate can be rejected. It implies, that the heart rate is independed on the environment of the experiment participants ( $p$-value $=0.061$ ).

Next were used paired tests (Wilcoxon signed-rank test, paired t-test) for comparing the values of heart rate of respondents measured before staying in a noisy environment in first experimental measurement (BEFORE1) and the values of heart rate of respondents measured before staying in a noisy after one year (BEFORE2). Testing shows, that there are statistically significant differences between these files BEFORE1 and BEFORE2.

Figure 2 shows the statistically evaluated heart rate of respondents from experiment after one year with chart of averages and $95 \%$ - confidence interval.

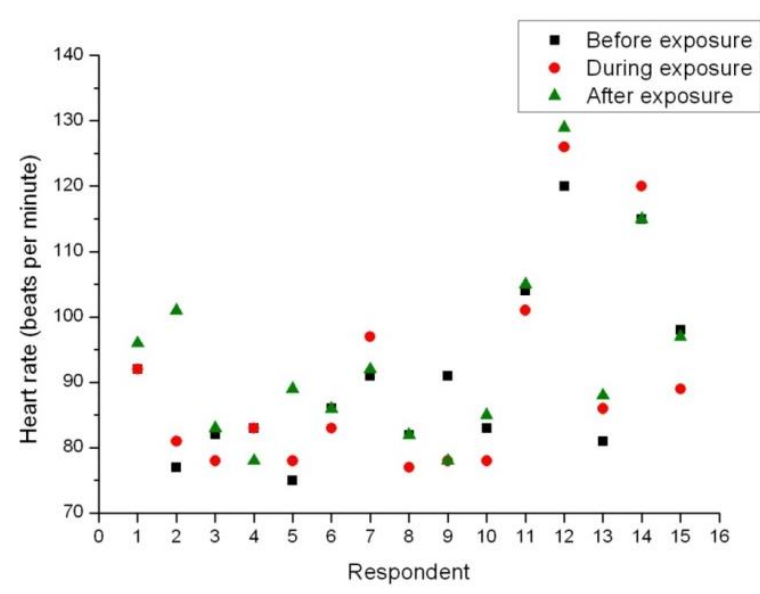

Figure 2. Chart of averages and $95 \%$ - confidence interval from measurement after one year

\subsection{Comparison of the results from experimental measurement of non-auditory effect of noise on human before and after one year}

Comparing results from two experimental measurements of non-auditory effects of noise in one year repeatability Table 5 presents parameter characteristic of 14 respondents in previous year (excluding respondent no.11).

Table 5. Parameter characteristics of the respondents involved in the experiment $(n=14)$

\begin{tabular}{llcccc}
\hline Parameters & Average & $\begin{array}{c}\text { Standard } \\
\text { deviation }\end{array}$ & Maximum & Minimum \\
\hline $\begin{array}{l}\text { Before } \\
\text { exposure }\end{array}$ & 78 & 18.90 & 107 & 57 \\
$\begin{array}{l}\text { Heart } \\
\text { rate }\end{array}$ & $\begin{array}{l}\text { During } \\
\text { exposure } \\
\text { After } \\
\text { exposure }\end{array}$ & 83 & 14.80 & 107 & 61 \\
\hline
\end{tabular}

Table 6 presents parameter characteristic of 14 respondents after year (excluding respondent no.11). Standard deviation is in this case lower (11.02) like it was in first measurement before year (18.90). Other values are in this case higher.

Table 6. Parameter characteristics of the respondents involved in the experiment after year

\begin{tabular}{ll|cccc}
\hline \multicolumn{2}{c}{ Parameters } & Average & $\begin{array}{l}\text { Standard } \\
\text { deviation }\end{array}$ & Maximum & Minimum \\
\hline & $\begin{array}{l}\text { Before } \\
\text { exposure }\end{array}$ & 88.57 & 11.02 & 115 & 75 \\
$\begin{array}{l}\text { Heart } \\
\text { rate }\end{array}$ & $\begin{array}{l}\text { During } \\
\text { exposure }\end{array}$ & 87.21 & 12.11 & 120 & 77 \\
& $\begin{array}{l}\text { After } \\
\text { exposure }\end{array}$ & 91.07 & 10.71 & 115 & 78 \\
\hline
\end{tabular}

With Shapiro-Wilk test we verify normality of data. The results of the testing show that normality condition is not fulfilled in the set BEFORE1 ( $p$-value $=0.039$ ) and in the set DURING2 ( $p$ value $=0.005$ ). 
Friedman test for set of measured files after one year shows, that the null hypothesis about accidental influences on the heart activity is again rejected

We can assume, that the value of heart rate does not depend on the environment in which the respondents are ( $p$-value=0.096). The result does not change also in the case of older data. Also in case excluding respondent no.11, there is a significant difference in heart rate between respondents before exposure in noisy environment and during exposure in noisy environment.

Paired tests (Wilcoxon signed-rank test, paired t-test) show, that also in this case there are statistically significant differences between sets BEFORE1 and BEFORE2 and also between sets AFTER1 and AFTER2.

\section{PROPOSAL OF METHODOLOGY OF NOISE RISK ASSESSMENT}

Risk management represents a process of studying and monitoring what can cause damage at a workplace in the form of physical injury or damage to health.

This process is possible to describe schematically in the following points:

- a description of a system and identification of dangers and threats, defining of possible consequences (e.g. damage to health),

- an estimate of risk and its evaluation,

- the setting of corrective measures with the goal of reducing risk.

Risk analysis also identifies the probability and range of consequences a negative event following from a given work or other activity. Risks are then estimated on the basis of the identified dangers. With the assessment of risk on the basis of an analysis of threats, the seriousness of the estimated size of the risk is assessed and the necessity to reduce it is evaluated. A component of risk management of the basis of its assessment is the proposal of measures, their implementation and the monitoring of their effectiveness .

With estimates of the probability of damage, it is necessary to take these viewpoints into consideration:

- the endangered persons,

- the type, frequency and duration of a threat - estimating the consequences requires that the long-term effect also be noted,

- the relationship of exposure and its effects - the relationship between the working of the danger and its effects in any dangerous situation must be considered. It is also essential to take into consideration a threat which is activated and its synergic effect,

- human factors, e.g. the interaction of persons, education, the degree of fatigue, ergonomic viewpoints, etc.

The conditions for the origin of damage, which can be an injury but also damage to health which has a chronic character with a long-lasting course. Dangerous situations, during which damage originates in consequence of cumulative working during a certain period of time (the non-auditory effects of noise), need to be resolved in a different way than situations during which sudden unexpected damage occurs [Balážiková 2016]. The probability of damage (consequence) arising depends on the cumulative exposure to the threat. Therefore, the exceeding of a certain level or measure above which the cumulatively working can cause damage to health can be considered as a dangerous event. Several exposures with different time durations and relevant doses can create an overall dosage, e.g. with hearing loss the dosage depends on the noise levels.

The first step with risk assessment is the identification of threats. The aim of threats identification is the creation of a list of threats which enable possible accident scenarios to be described with respect to when and how damage may arise in a given threat [Maščenik 2009].

The method of risk assessment is proposed specifically for the reason of long-term noise exposure (even sub-limit noise values), which can later lead to chronic damage to health. From the long-term perspective this can lead to non-auditory effects of noise which is necessary to capture in the beginning phase, for which the method proposed in this work can serve as an instrument.

The assessment of acoustic risks consists of a basic method for risk assessment, which is described in standard ard STN EN ISO 14121 - 2 Safety of Machines. Risk Assessment. Part 2: Practical instructions and examples of methods - Risk Matrix. The assessment of acoustic risks is made up of two Risk Matrices. The first is the matrix of auditory risks ( $R_{\text {audit. }}$ ) and the second is the matrix of non-auditory risks ( $\left.R_{\text {non-audit. }}\right)$. A risk matrix is a twoparametric register of the probability of a negative event and its consequence originating. The limits of probability in $R_{\text {audit. }}$ and $\mathrm{R}_{\text {non-audit. }}$ are created by legislative limit values of exposure to noise (Directive 2003/10/EC of the European Parlament and of the Council). Consequences are set by subjective feelings, or by quantitative values of non-auditory effects, e.g. in the case of irritation of the automatic nervous system, this is an increasing of heart activity (frequency) and the working of the internal organs, raised blood pressure, and increased hormonal secretions, or in the case of the endocrine system, this is the release of catecholamine or cortisol with raised noise levels 17 [Balážiková 2012].

This proposed method for the assessment of acoustic risks is also applied in practice, where the non-auditory effects of noise were quantitatively described using the heart-rate that is the impact of noise on the cardiovascular system. The software processing of the developed method in the spreadsheet program Microsoft Excel for Microsoft Windows is in Figure 3.

The resulting value of the acoustic risk can have values between 1 to 75 . The weight of the risk is gradual with respect to the effects of noise and the exposure time. In making this assessment of acoustic risk using the proposed methodology in the context of this measurement, where the measured noise level $L_{A, e q}$ at the time of operation was $95.4 \mathrm{~dB}$, the acoustic risk value is 28,125 - a significant risk.

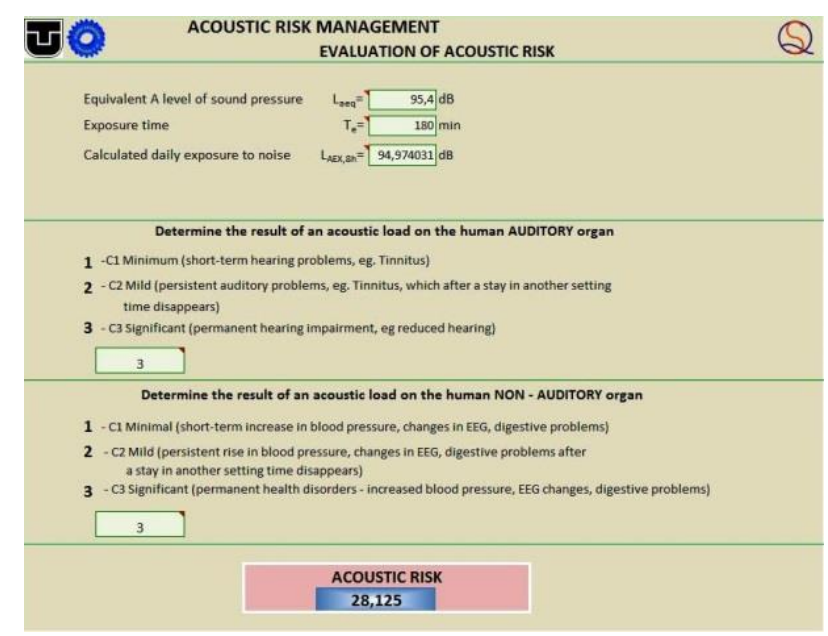

Figure 3. Software for the assessment of acoustic risks

Possibilities for determining the integrated values of acceptable risk:

- the acceptability of the vibro-acoustic environment can be assessed as the tolerable measure of the load by unfavourable 
conditions of the simultaneous working of noise and mechanical oscillation in the work environment,

- the vibro-acoustic acceptability of the environment can be evaluated according to the criteria of subjective interruption, interference with the activity of a person or performance, safety of the work and protection of health or with their free combination [Bičejová 2009].

\section{CONCLUSION}

It is a well- known fact, that a long-time and repeating stay in the noisy area is unfavourable for hearing. However, it is not well known usually also another important fact that the auditory organ is not the sole point of the human body, which is able to percept the noise. The noise is affecting the whole human body, especially the cardio-vascular system, the central nervous system and the vegetative nervous system.

Many people, however, believe that noise produced by an individual, who also makes decisions about its origination and transmission, is not serious enough to be reduced or eliminated. This could be caused by the fact that consequences are not immediately obvious.

The quality of working life is influenced by a number of factors of physical and psychosocial nature. Individual factors can both positively and negatively affect the health of the individual, which may then be manifested in the form of short- or long-term health problems.

Paper was focused on the analysis of the risk factor, namely noise, on human health. In the presented experiment was pointed out that noise may affect the cardiovascular system, whose risk in terms of time exposure is increasing. If we were based on the definition of risk $\mathrm{R}=\mathrm{P} \times \mathrm{C}$ (where $\mathrm{R}$ - risk, $\mathrm{P}$ probability, C - effect), the longer the probability of noise exposure is, the higher the presumption of impacts on the auditory apparatus and the non-auditory effects of noise and after that the decreasing the quality of work.

\section{ACKNOWLEDGMENTS}

An article was elaborated within APVV-15-0351 Development and application of risk management models in terms of technological systems in line with the industry (Industry) 4.0.

This contribution is the result of the project VEGA no. 1/01210/18 Development of Smart factory comprehensive security implementation and verification methods as part of Industry Strategy 4.0.

\section{REFERENCES}

[Argalášová 2013] Argalášová, L., Lekaviciute J., Jeram S., Ševčíková L., Jurkovičová J. Environmental noise and cardiovascular disease in adults: Research in Central, Eastern and South-Eastern Europe and Newly Independent States. Noise Health, Noise Health, 2013, Vol. 15, pp. 22-31. doi 10.4103/1463-1741.107149

[Babisch 2011] Babisch, W. Cardiovascular Effects of Noise, Federal Environmental Agency, Berlin. Encyclopaedia of Environmental Health, 2011, pp. 532-542, ISBN 978-0-44452272-6

[Babisch 2017] Babisch, W. Cardiovascular effects of noise on man. Acoustical Society of America. [cit. 17-07-2017] Available from:http://acoustics.org/cardiovascular-effects-of-noise-onman-wolfgang-babisch/

[Balážiková 2012] Balážiková, M., Sinay, J. Implementation of auditory and non-auditory effects of noise in the risk assessment process in mechanical engineering. Procedia Engineering, 2012, Vol. 48, pp. 621-628. ISSN 1877-7058.

[Balážiková 2016] Balážiková, M., Tomašková, M., Dulebová, M. Study of non-auditory effects of noise. Modern Machinery, 2016, pp. 912-917. ISSN 1805-0476.

[Basner 2014] Basner, M. et al. Auditory and non-auditory effects of noise on health. Lancet, 2014, Vol. 383, pp. 1325-1332. doi: 10.1016/S0140-6736(13)61613-X

[Bičejová 2009] Bičejová, L., Kmec, J. Noise and vibration evaluation of water jet material cutting working surroundings. Annals of Faculty Engineering Hunedoara - International Journal of Engineering, 2009, Vol. 7, pp. 139-144. ISSN 1584-2665.

[Deshaies 2015] Deshaies, M. et al. Noise as an explanatory factor in work-related fatality reports. Noise Health, 2015, Vol. 17, pp. 294-299. doi: 10.4103/1463-1741.165050

[Ismaila 2014] Ismaila S.O., Odusote A. Noise exposure as a factor in the increase of blood pressure of workers in a sack manufacturing industry. Beni-Suef University Journal of Basic and Applied Sciences, 2014, Vol. 3, Issue 2, pp. 116-121. doi: 10.1016/j.bjbas.2014.05.004

[Knežo 2011] Knežo, D., Andrejiová, M., Ižaríková, G. Basics of statistical methods. Study liturature edition, Košice, 2011. ISBN 978-80-553-0841-8

[Maščenik 2017] Maščenik, J. Monitoring of parameters directly influencing performance transfer by belt gear. MM Science Journal, 2017, Vol. December, pp. 1959-1962. ISSN 1803-1269. [Meddeb 2016] Meddeb W., Tadjine K. Assessment of Exposure to Noise of Workers to a Reinforcing Bar Rod Mill ArcelorMittal Algeria. Archives of acoustics, 2016, Vol. 41, No. 2, pp. 339-344. doi: 10.1515/aoa-2016-0035

[Molesworth 2013] Molesworth, B. R. C., Burgess M. Improving intelligibility at a safety critical point: In flight cabin safety. Safety Science, 2013, Vol. 51, Issue 1. pp. 11-16. doi.org/10.1016/j.ssci.2012.06.006

[Nilsson 2007] Nilsson, M.E. Soundscape quality in urban open spaces. Proc. Inter. Noise, 2007. Paper IN07-115. [cit. 10-092017].

www.ljudlandskap.acoustics.nu/downloads/publikationer/ljudl andskap/papers_in2007/Soundscape_quality.pdf

[Prashanth 2008] Mahendra Prashanth K. V., Sridhar V. The relationship between noise frequency components and physical, physiological and psychological effects of industrial workers. Noise Health, 2008, Vol. 10, pp. 90-98. doi: 10.4103/14631741.44347

[Razavi 2014] Razavi, H., Ramezanifar, E., Bagherzadeh, J. An economic policy for noise control in industry using genetic algorithm. Safety Science, 2014, Vol. 65, pp. 79-85. https://doi.org/10.1016/j.ssci.2013.12.010

[Šolc 2011] Šolc, M. Noise from the working environment as one of the important factors affecting human quality of life (Hluk z pracovného prostredia ako jeden z významných faktorov ovplyvňujúcich kvalitu života človeka). Prevence úrazů, otrav a násilí, 2011, Vol. 7, pp. 85-91. ISSN 1801-026. (in Slovak)

[Vianna 2015] De Paiva Vianna K.M., Alves Cardoso M.R., Rodrigues R.C. Noise pollution and annoyance: An urban soundscapes study. Noise Health, 2015. Vol. 17, pp.125-133. doi: 10.4103/1463-1741.155833

\section{CONTACTS:}

Assoc. Prof. Michaela Balážiková, PhD.

Technical University of Kosice

Faculty of Mechanical Engineering

Department of Safety and Quality

Letna 9, 04200 Kosice, Slovakia

www.tuke.sk 